\title{
Traceability Features of the Electric Power Unit in Ukraine
}

\author{
Oleh Velychko ${ }^{1}$, and Stanislav Karpenko ${ }^{1, *}$ \\ ${ }^{1}$ SE “Ukrmetrteststandard”, 03143, Metrolohichna str. 4, Kyiv, Ukraine
}

\begin{abstract}
The paper describes some aspects concerning the realization of the electric power unit traceability in Ukraine in the CIPM MRA understanding through participation in Key and Supplementary Comparisons of national standards and in the ILAC MRA understanding through participation in inter-laboratory comparisons. The authors have demonstrated comparative analysis of EURAMET.EM-K5.1, COOMET.EM-S2, COOMET.EM-K5 comparisons results and practically realized the procedure for realisation traceability of the electric power unit in Ukraine.
\end{abstract}

\section{Introduction}

It should be mentioned that the recognition of the importance of metrologically traceable measurement results significantly increased over the last five years, especially as part of the calibration laboratory (CL) accreditation programs. The International Bureau of Weights and Measures (BIPM), the International Organization of Legal Metrology (OIML), the International Laboratory Accreditation Cooperation (ILAC) and the International Organization for Standardization (ISO) are four international bodies responsible for metrology, accreditation and standardization worldwide have drawn up this declaration on metrological traceability (MT) [1].

The key documents to this declaration are Guide to the Expression of Uncertainty in Measurement (GUM) - JCGM 100 [2] and International Vocabulary of Metrology (VIM) JCGM 200 [3].

The definition of MT that is globally accepted in the metrology community according to VIM is "property of a measurement result whereby the result can be related to a reference through a documented unbroken chain of calibrations, each contributing to the measurement uncertainty" [3].

Also international standard ISO/IEC 17025 [4] details the expected requirements and provides further information on MT.

The MT allows the comparison of the accuracy of measurements worldwide according to the standardized procedure for estimating measurement uncertainty.

International measurement standards realize within a chain of MT, the units of measurement with the highest accuracy. International comparison of national standards of

*Corresponding author: s.r.karpenko86@gmail.com 
the highest quality determines the value of the international standard according to CIPM MRA-D5 [5].

National measurement standard serves as a reference for calibration of standards of lower precision. Always national measurement standard is kept in a National Metrology Institute (NMI) or Designated Institutes (DI) and reference standards in an accredited CL for calibrations not requiring the highest accuracy.

At each stage of MT, one loses a certain degree of precision. In such case the highest level standards are the national measurement standards, known with the greatest level of precision, and the lower level standards will have been determined to a lower level of precision.

The MT of measurement results at different levels of metrological work is presented in $[6,7]$. MT at the highest metrological level is carried out through participation in international comparisons of the national standards of NMI or DI. In such case MT at lower measurement level is carried out through the calibration procedures of working standards by both NMIs or DIs and accredited CLs [8].

The main goal of paper is to describe some aspects concerning the realization of. The electric power unit MT in Ukraine in the CIPM MRA understanding through participation in Key (KC) and Supplementary Comparisons (SC) of national standard at international level and in national level through the participation in inter-laboratory comparisons (ILC).

\section{Traceability chain of the physical quantity}

It should be mentioned that metrological activities, calibration, testing and measurements are main inputs to provide the quality of industrial and life related activities and processes. The demonstration of MT in different levels becomes just as important as the measurement itself. Recognition of metrological competence at each level of the MT chain can be established through mutual recognition agreements CIPM MRA [9] and ILAC MRA [10], and also through accreditation.

The MT chain for the physical quantity can be shown Figure 1, is an unbroken chain of international and inter-laboratory comparisons with having stated uncertainties.

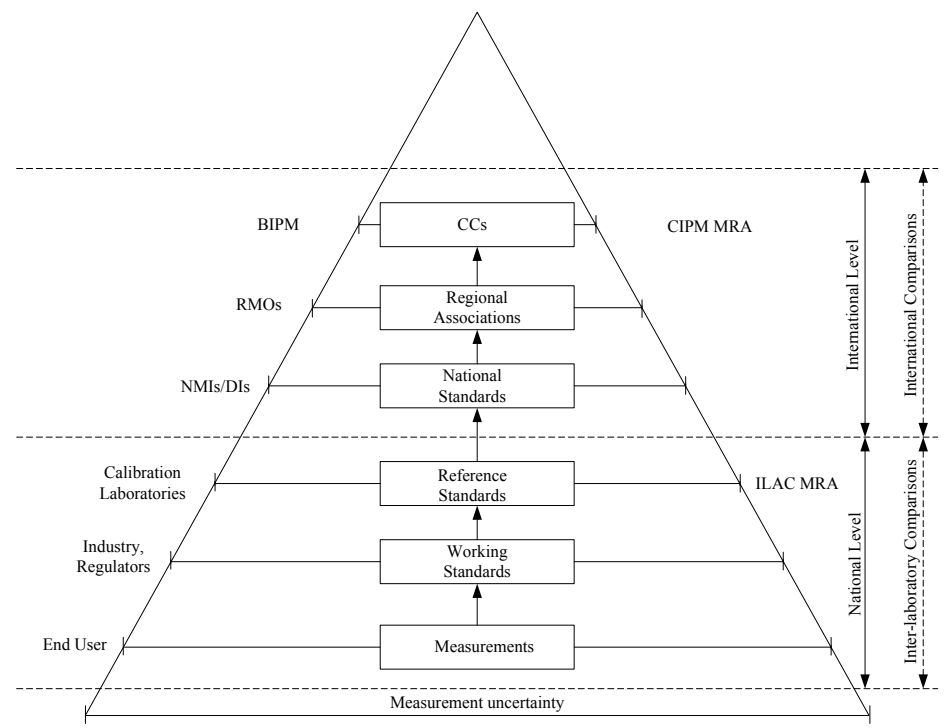

Fig. 1. Traceability chain of the physical quantity. 
The end user can obtain MT to the highest international level either directly from a NMI or from an accredited CL. Based on the Figure 1 it can be set the ratio of extended uncertainties:

$$
U_{C C}<U_{R M O}<U_{N M I / D I}<U_{C L}<U_{I / R}<U_{E U}
$$

\section{Realization of CIPM MRA by means of participation in international comparisons of the electric power unit}

National standard of electric power and power factor units of Ukraine was designed for reproduction and storage of electric power unit from 0.01 to $72000 \mathrm{~W}$ (in single-phase mode) in the frequency range from 40 to $70 \mathrm{~Hz}$.

National standard of electric power and power factor units which is stored and operated since 2002 in SE "Ukrmetrteststandard" (UMTS) see on Figure 2. Definitely modernization of National standard has become a key point in the need to revise published Calibration and Measurement Capabilities (CMCs) of the electric power unit in order to improve them.

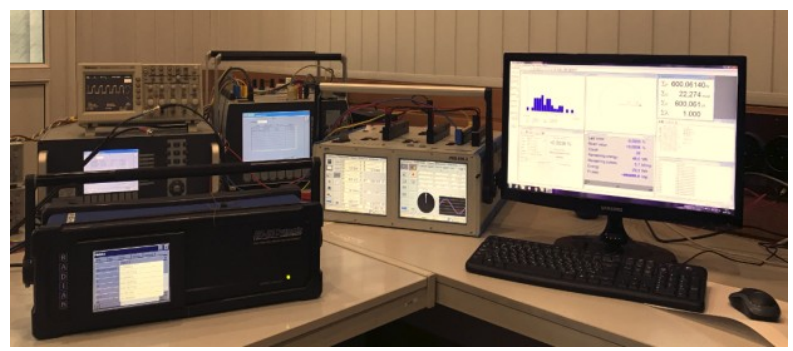

Fig. 2. National Standard of electric power and power factor units of Ukraine.

The MT chain for realization the requirements of CIPM MRA [9] by means of participation in international comparisons of the physical quantity, is shown on Figure 3, is an unbroken chain of international comparisons with having stated uncertainties.

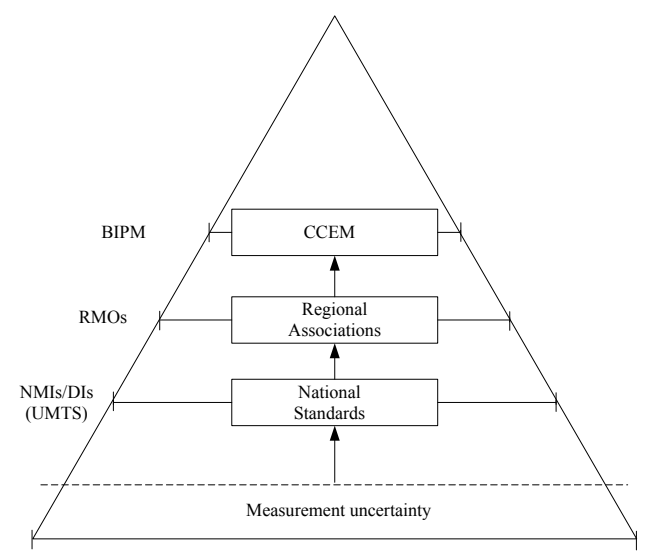

Fig. 3. Traceability chain for realization the requirements of CIPM MRA.

\subsection{Key Comparison of power EURAMET.EM-K5.1}

In 2007 UMTS took part as the participant in KC EURAMET.EM-K5.1 [11] with the aim of publishing CMCs of electric power unit in the BIPM Key Comparison Database (KCDB). It was decided to perform the comparison at $120 \mathrm{~V}, 5 \mathrm{~A}, 53 \mathrm{~Hz}$, power factors 1 , 
$0.5 \mathrm{Lead} / \mathrm{Lag}$ and $0.0 \mathrm{Lead} / \mathrm{Lag}$ in order to be in line with the global Consultative Committee for Electricity and Magnetism (CCEM) comparison CCEM-K5 [12].

UME (Turkey NMI) was proposed as the pilot laboratory. PTB (Germany NMI) the pilot laboratory of the previous KC EURAMET.EM-K5 [13] was proposed to play a key role in KC EURAMET.EM-K5.1 by taking measurements as much as the number of measurements taken by the pilot laboratory. The measurement results of PTB were used to estimate the drift effect of the travelling standard (TS).

Also, PTB was proposed to be the linking NMI for the linking process between CCEM-K5 $\mathrm{KC}$ of power [12] and EURAMET.EM-K5.1 KC of power [11] since PTB would be the only NMI which participated in both comparisons.

At first seven NMIs (UME, PTB, DMDM, NCM, OMH, SIQ and SMU) had agreed to participate. During the KC SIQ withdrew from participation, but during 2003 to 2006 six additional NMIs (MIKES, VSL, INM, LNE, NPLI and UMTS) were included in the list of $\mathrm{KC}$.

HEG C1-2 Power-Converter was selected as TS as well as in EURAMET.EM-K5. HEG C1-2 is based on a time-division multiplication scheme. It has electrically isolated voltage and current inputs on the front panel. There is only one voltage range which is equal to $120 \mathrm{~V}$ and also, only one current range equal to $5 \mathrm{~A}$. The TS is configured as an AC-powerto-DC-voltage transducer, with a nominal full-scale DC output of $10 \mathrm{~V}$. Before comparison started TS had been regularly monitored for several years. At the end of EURAMET.EM-K5.1 [11] was prepared and published final report in the BIPM KCDB. As an example, results of NMI participants for $\mathrm{PF}=1.0$, and $53 \mathrm{~Hz}$ are illustrated on Figure 4 .

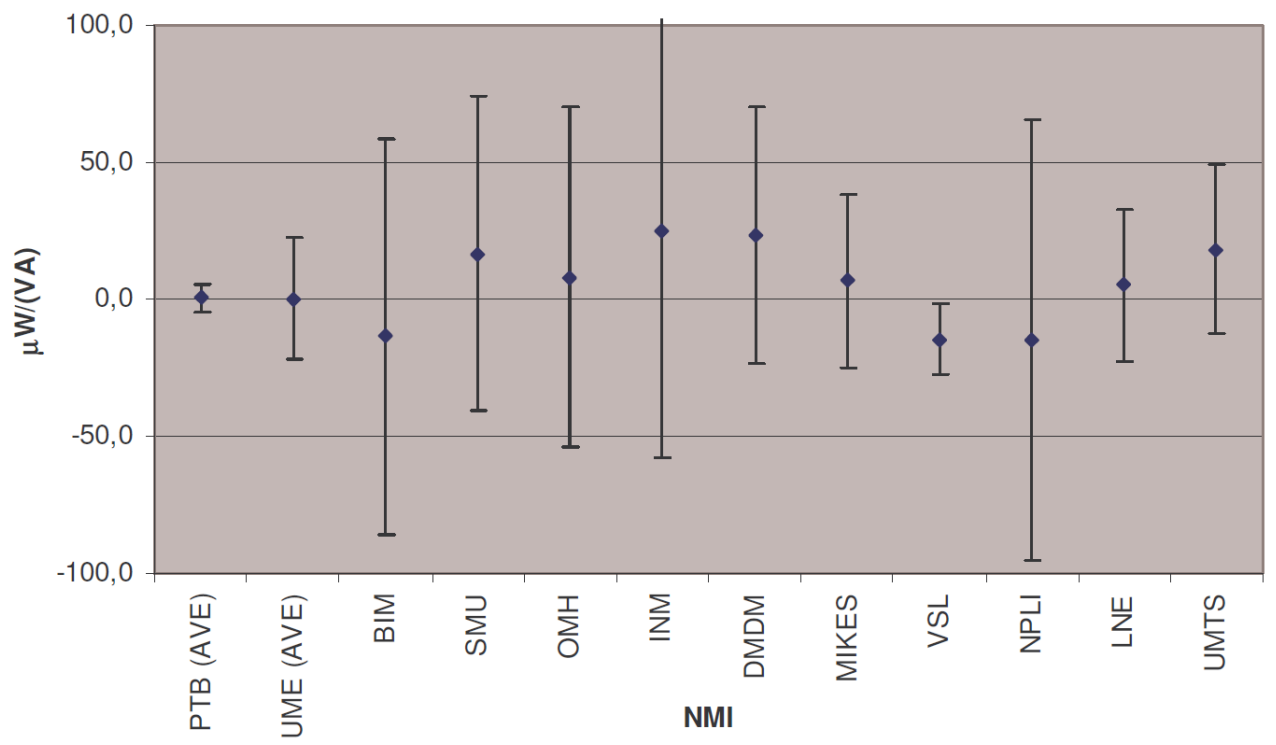

Fig. 4. Degree of equivalence for NMI participants of EURAMET.EM-K5.1 for PF = 1.0, $53 \mathrm{~Hz}$.

\subsection{Supplementary Comparison of power COOMET.EM-S2}

In 2008 to support the published CMCs, UMTS organized SC of power COOMET.EM-S2 [14] and were proposed to be the pilot laboratory. It was decided to perform the comparison at $120 \mathrm{~V}, 5 \mathrm{~A}, 50 \mathrm{~Hz}$ and $53 \mathrm{~Hz}$, power factors $1,0.5 \mathrm{Lead} / \mathrm{Lag}$ in order to be in line with EURAMET.EM-K5.1 KC of power. Only three NMIs took part in this comparison UMTS (Ukraine), BelGIM (Belarus) and BIM (Bulgaria). 
Radian Research RM 15-04 was selected as TS in a framework of COOMET.EM-S2. RM 15-04 is precision single-phase electric power meter, works on principles of digital processing of electrical current and voltage signals and well-suited for test applications that require multiple measurements with high accuracy and stability. In addition to its auto ranging capabilities, RM 15-04 features three summing current inputs which can be used to perform closed link testing.

As an example, results of NMI participants for $\mathrm{PF}=1.0$, and $50 \mathrm{~Hz}$ are illustrated on Figure 5.

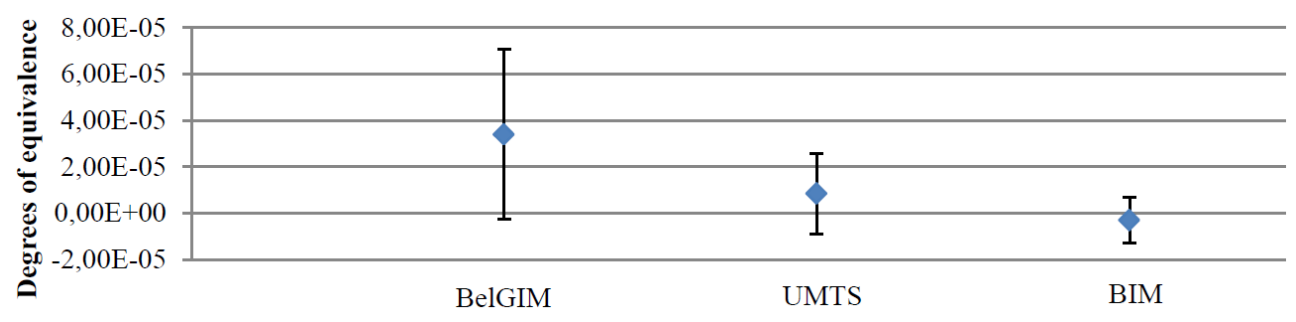

Fig. 5. Degree of equivalence for NMI participants of COOMET.EM-S2 for PF = 1.0, $53 \mathrm{~Hz}$.

For the first time the procedure was proposed for linking the results of $\mathrm{KC}$ EURAMET.EM-K5.1 and SC COOMET.EM-S2 to those national metrology institutes which have also taken part in both comparisons [15].

The RMO results of $\mathrm{KC}$ and $\mathrm{SC}$ are linked by a correction factor which is determined as the difference of degrees of equivalence from the results of the participating laboratories in both comparisons. Furthermore, we determined the uncertainty of the correction factor which is then used in the calculation of the corrected degrees of equivalence and their uncertainties. The proposed linking procedure is illustrated for real data set where the results of EURAMET KC and COOMET SC for electrical power (EP) is linked see Figure 6 [16].

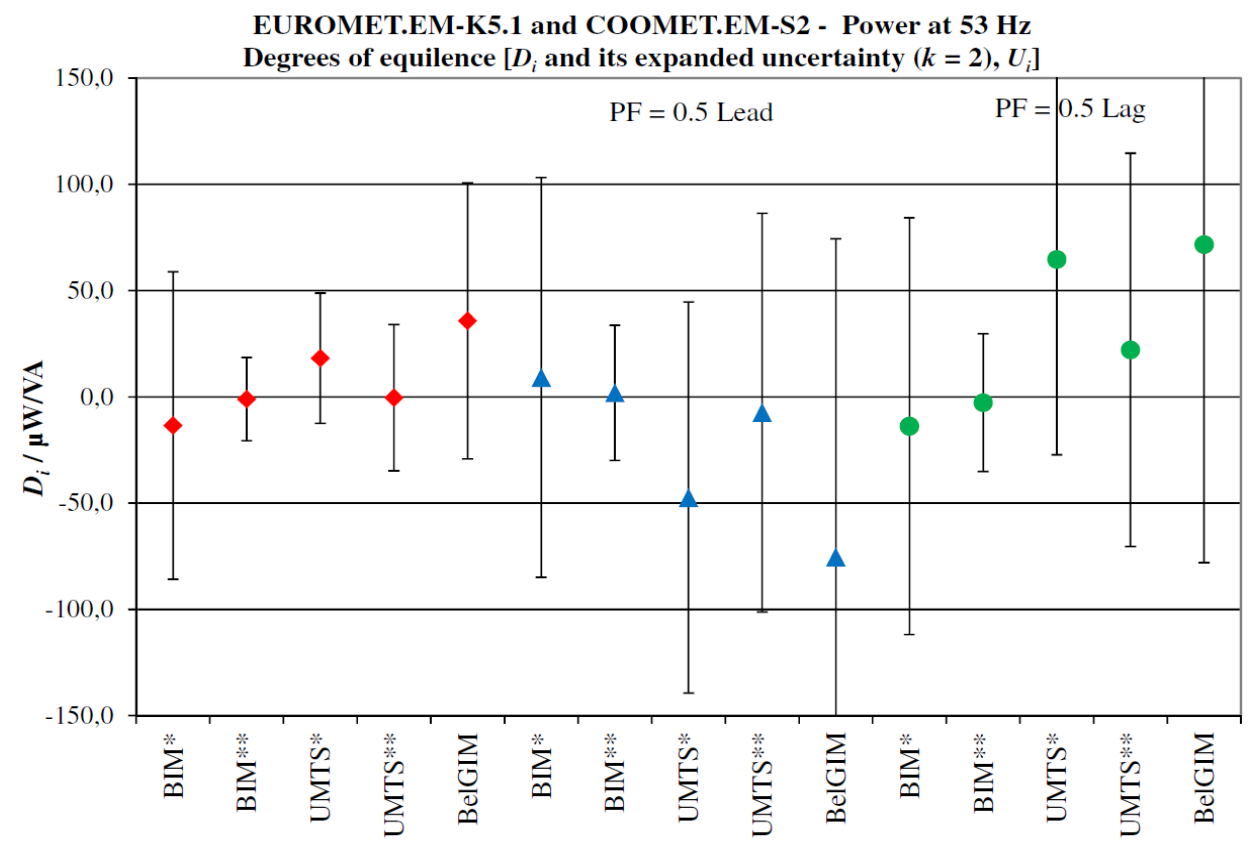

Fig. 6. Degrees of equivalence for participants of COOMET.EM-S2, and corrected degrees of equivalence for BelGIM in terms of RV K5.1. 


\subsection{Key Comparison of power COOMET.EM-K5}

To support the CMCs declared by members of COOMET, EURAMET, APMP, GULFMET and AFRIMET in the framework of the CIPM-MRA UMTS organized and piloted KC of power COOMET.EM-K5 in 2016-2018. The KC of power were performed at $120 \mathrm{~V}, 5 \mathrm{~A}$, 50 and $53 \mathrm{~Hz}$, power factors $1,0.5 \mathrm{Lead} / \mathrm{Lag}$ and $0.0 \mathrm{Lead} / \mathrm{Lag}$ in order to be in line with the global CCEM KC [17].

Selected TS is Radian Research RD-33-332 (RD-33-332) with guaranteed accuracy of $0.01 \%$. RD-33-332 is three-phase electric power meter, works on principles of digital processing of electrical current and voltage signals. TS compared at 14 NMIs to establish the relationship between the electrical units of AC power at these laboratories: UMTS (Ukraine); BelGIM (Belarus); VNIIM (Russia); GEOSTM (Georgia); CMS (Kyrgyzstan); UME (Turkey); SMU (Slovakia); LEM-FEIT (R. Macedonia); NIM (China); MASM (Mongolia); QCC EMI (United Arab Emirates); SASO-NMCC (Saudi Arabia), and NIS (Egypt). MASM (Mongolia); CMS (Kyrgyzstan); LEM-FEIT (Republic of Macedonia); QCC EMI (United Arab Emirates); SASO-NMCC (Saudi Arabia) and NIS (Egypt) joined to $\mathrm{KC}$ in 2017. KazInMetr (Kazakhstan) was excluded in 2018 from the list of participants of $\mathrm{KC}$ for technical reasons.

The traceability to the SI of standards was provided to pilot NMI. All of the participating NMIs made measurements of $50 / 53 \mathrm{~Hz}$ Power. UMTS, BelGIM, GeoSTM, SMU, NIS, and LEM FEIT measurements of power are traceable to PTB. PTB participated in CCEM-K5 and EURAMET.EM-K5.1, and also was a pilot laboratory for EUROMET.EM-K5.

MASM power measurements are traceable to NIM and KRISS. NIM participated in CCEM-K5 KC and was a pilot laboratory in APMP.EM-K5.1.

QCC EMI power measurements are traceable to NMIA. NMIA was a pilot laboratory in APMP.EM-K5.

COOMET.EM-K5 KC of power will be linked to CCEM-K5 KC of power. NIM (China NMI) and VNIIM (Russia NMI) were proposed to be the linking NMIs for the linking process between CCEM-K5 $\mathrm{KC}$ of power and the COOMET.EM-K5 KC of power. Relevance of the comparison results are expected at the level of better than $0.005 \%$.

After analysis COOMET.EM-K5 KC of power positive results general conclusion can be made CMCs of the electric power unit of Ukraine will be improved. As an example, results of NMI participants for $\mathrm{PF}=1.0$, and $50 \mathrm{~Hz}$ are illustrated on Figure 7.

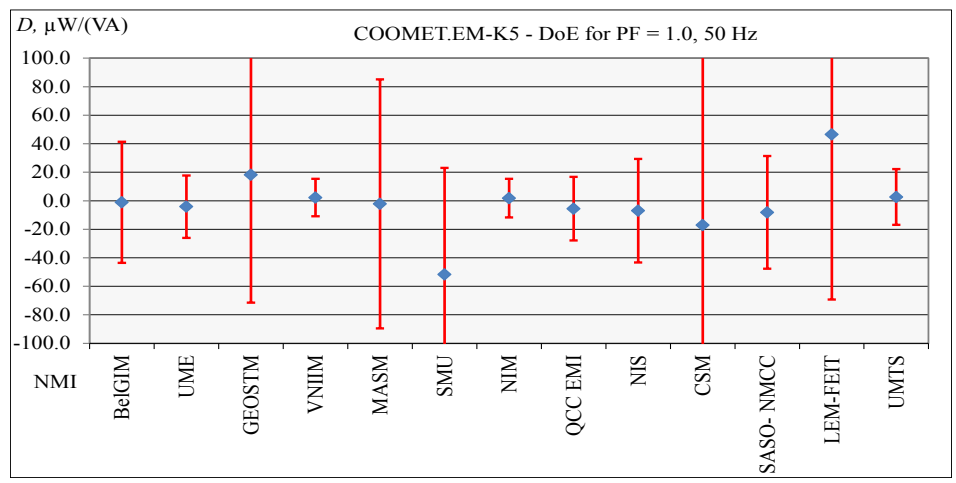

Fig. 7. Degree of equivalence for NMI participants of COOMET.EM-K5 for PF $=1.0,50 \mathrm{~Hz}$.

The procedure was proposed for linking the results of KC EURAMET.EM-K5.1 and KC COOMET.EM-K5 to those NMIs which have also taken part in both comparisons, see Figure 8 . 
UME (Turkey), SMU (Slovakia) and UMTS (Ukraine) are the NMIs which took part in both comparisons. UME was the pilot laboratory of KC EURAMET.EM-K5.1 and UMTS was the pilot laboratory of KC COOMET.EM-K5. Both NMIs improved their results.

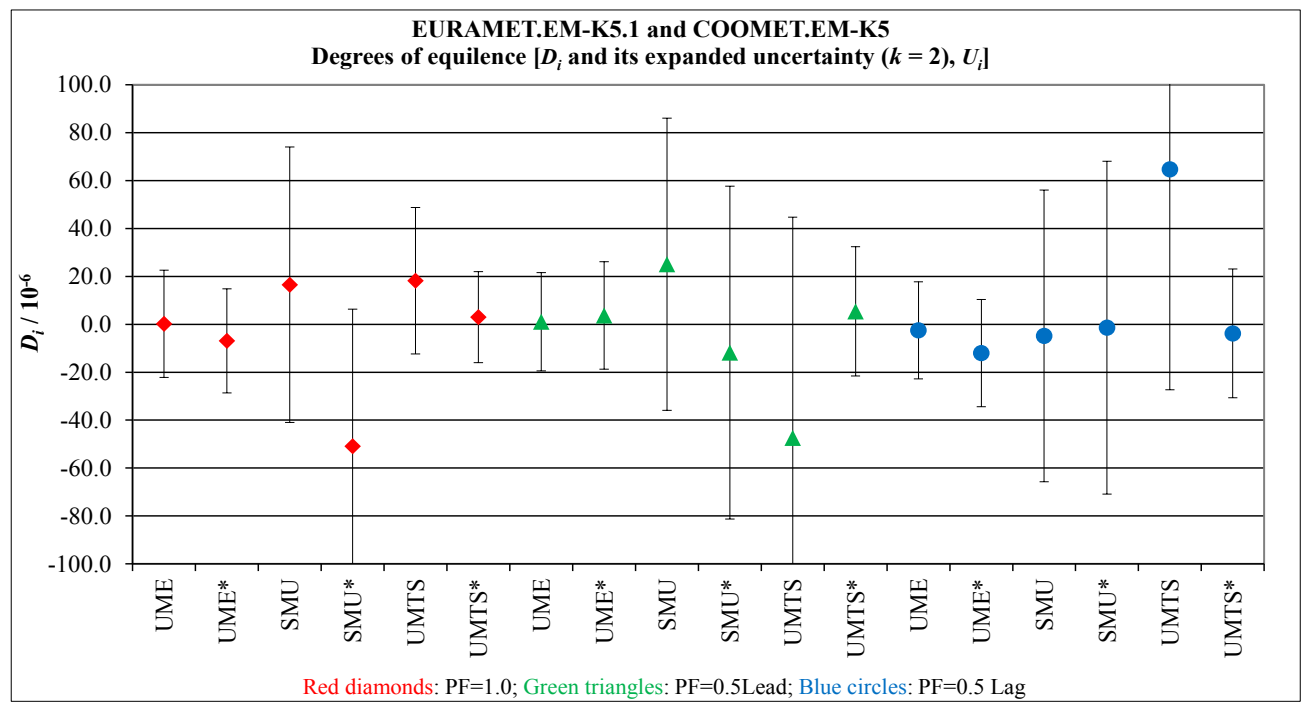

Fig. 8. Degrees of equivalence for participants in both comparisons EURAMET.EM-K5.1 and COOMET.EM-S2 and their corrected degrees of equivalence.

It was also determined the uncertainty of the correction factor which is then used in the calculation of the corrected degrees of equivalence and their uncertainties.

\section{Realization of ILAC MRA by means of participation in inter- laboratory comparisons of the electric power unit}

The MT chain for realization the requirements of ILAC MRA [10] and international standard ISO/IEC 17043 [18] by means of participation in ILC of the electric power unit, is shown on Figure 9, is an unbroken chain of calibrations with having stated uncertainties [19].

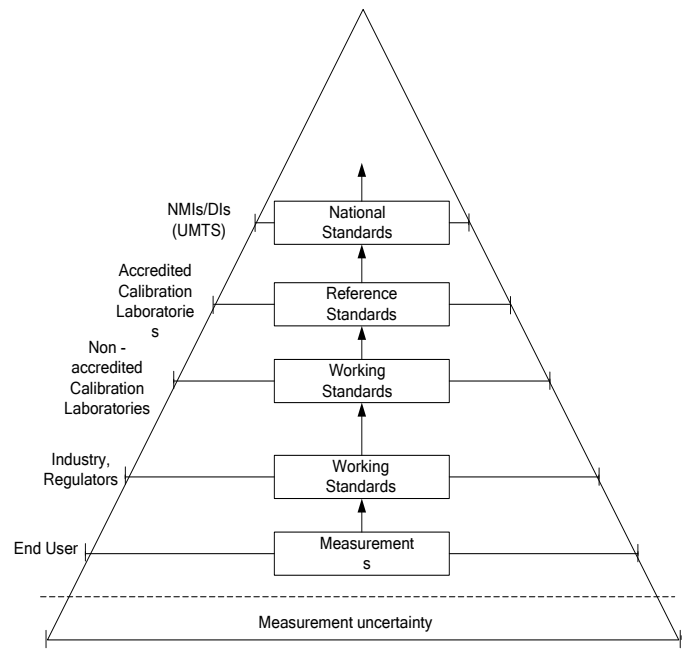

Fig. 9. Traceability chain for realization the requirements of ILAC MRA. 
There are about twenty Ukrainian accredited CL's. UMTS provided and carried out the ILC as reference measurements provider for all Ukraine accredited CL's for electric power measurements at industrial frequency.

Only seven CL's (Lab1-7) are obligated to participate in ILC. All the participated CL's did measurements according the Technical Protocol which was sent before the execution of ILC. But evaluation of expanded uncertainty was done according to calibration procedures developed by participated CL's.

The main goal of this ILC was the assessment of CL's capabilities that perform calibration in EP measurement. This ILC helped to verify first of all technical competence of the staff of participated CL's, their technical and calibration procedures, environmental conditions.

It should be mentioned that all Ukrainian CL's are accredited according to [4] and are equipped with single/three-phase watt meters with accuracy classes $0.02 \%, 0.05 \%, 0.1 \%$, $0.2 \%$.

The measurement points were established according the participated CL's accreditation schedules and international practice of organizing comparisons. The radial scheme was used so the TS is returned to the UMTS as the reference laboratory (RL) after each measurement at a participated CL [20, 21].

The assigned values taken into account were the means of measurement values by the $\mathrm{RL}$ for each established point [22]. Figure 10 shows only the results for $50 \mathrm{~Hz}$ measurements of the ILC as an example.

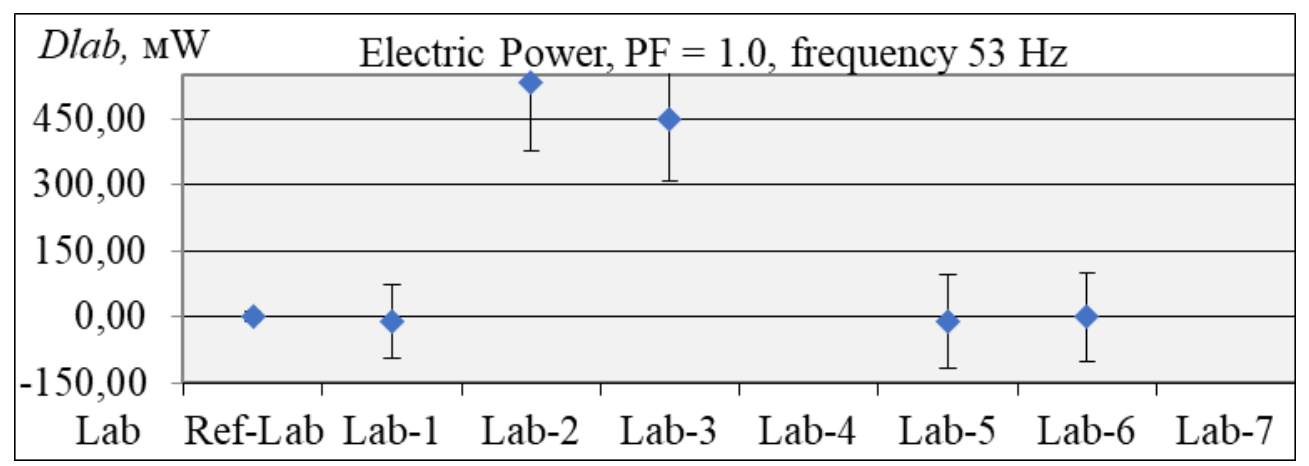

Fig. 10. Calibration results of inter-laboratory comparison for $\mathrm{PF}=1.0$, frequency $50 \mathrm{~Hz}$.

\section{Providing calibration service in Ukraine}

UMTS as NMI of Ukraine provide calibration service for all power plants and energy systems. Table 1 show the amount of single/three-phase watt meters with accuracy classes $0.02 \%, 0.05 \%, 0.1 \%$, and $0.2 \%$ which were calibrated in UMTS laboratory from 2013 to 2019.

UMTS provided calibration service for 2294 precision single/three-phase working standards of electric power and energy for 7 years term for power plants and energy systems. 
Table 1. Formatting sections, subsections and subsubsections.

\begin{tabular}{|c|c|c|c|c|}
\hline Year & $\begin{array}{c}\text { Total } \\
\text { amount }\end{array}$ & $\begin{array}{c}\text { Accuracy classes } \\
\mathbf{0 . 1} / \mathbf{0 . 2} \%\end{array}$ & $\begin{array}{c}\text { Accuracy } \\
\text { classes 0.05 \% }\end{array}$ & $\begin{array}{c}\text { Accuracy classes } \\
\mathbf{0 . 0 2} \%\end{array}$ \\
\hline 2013 & 417 & 301 & 110 & 6 \\
\hline 2014 & 386 & 283 & 90 & 13 \\
\hline 2015 & 371 & 271 & 94 & 6 \\
\hline 2016 & 347 & 251 & 93 & 3 \\
\hline 2017 & 367 & 284 & 81 & 2 \\
\hline 2018 & 380 & 319 & 61 & 33 \\
\hline Total & 2294 & 1726 & 537 & $1.4 \%$ \\
\hline Relative total & $100 \%$ & $75.2 \%$ & $23.4 \%$ & \\
\hline
\end{tabular}

\section{Conclusion}

The paper is devoted to a discussion of issues concerning the realization of the electric power unit traceability in Ukraine in the CIPM MRA understanding through participation in Key Comparisons: EURAMET.EM-K5.1 and COOMET.EM-K5 (pilot laboratory UMTS) and Supplementary Comparison: COOMET.EM-S2 (pilot laboratory UMTS) of national standards for international level.

And in the ILAC MRA understanding through participation in inter-laboratory comparisons which also were piloted by UMTS as the NMI of Ukraine for local level.

The authors also have demonstrated comparative analysis of the provided calibration service for 2294 precision single/three-phase working standards of electric power and energy for 7 years term for power plants and energy systems in Ukraine.

UMTS as NMI of Ukraine provide MT in international and local levels.

\section{References}

1. Joint BIPM, OIML, ILAC and ISO declaration on metrological traceability, 6 (2018)

2. JCGM 100 Evaluation of measurement data - Guide to the expression of uncertainty in measurement (2008)

3. JCGM 200 International vocabulary of metrology - Basic and general concepts and associated terms (2012)

4. ISO/IEC 17025:2017 General requirements for the competence of testing and calibration laboratories (2017)

5. CIPM MRA-D5 Measurement comparisons in the CIPM MRA, 29

6. O. Velichko, Meas. Tech., Traceability of measurement results at different levels of metrological work, 52, 1242-1248 (2009)

7. ILAC P10:01 ILAC Policy on the Traceability of Measurement Results, 10 (2013)

8. O. Velychko, T. Gordiyenko, Metrological Traceability at Different Measurement Levels, 21 (2018)

9. CIPM MRA Mutual recognition of national measurement standards and of calibration and measurement certificates issued by national metrology institutes, 38-41 (1999)

10. ILAC MRA The ILAC Mutual Recognition Arrangement, 8

11. H. Çayci, Metrologia, Final report on key comparison EURAMET.EM-K5.1 (EURAMET Project No. 687): Comparison of 50/60 Hz power, 48, 01009 (2011)

12. N. Oldham, T. Nelson, N. F. Zhang, H.-k. Liu, Final Report of CCEM-K5 Comparison of 50/60 Hz Power, (2002) 
13. Final Report EUROMET.EM-K5 Comparison of 50/60 Hz Power (EUROMET Project 385), 64

14. O. Velychko, S. Karpenko, V. Gachok, A. Akhmadov, Metrologia, Final Report on COOMET 344/UA/05 Supplementary Comparison of 50/53 Hz Power (COOMET.EMS2), 52, 01008 (2015)

15. O. Velychko, S. Karpenko, Int. J. of Metr. \& QE, Linking results of key and supplementary comparisons of regional metrology organization for electrical power, 7 , 1-7 (2016)

16. S. Karpenko, O. Velychko, PTB-SEMINAR MATHMET 2016, Features of Linking the Results of Key and Supplementary Comparisons of RMO (2016)

17. Final Report COOMET.EM-K5 Comparison of 50/60 Hz Power, 136

18. ISO/IEC 17043 Conformity assessment. General requirements for testing laboratory qualifications, (2014)

19. I. Sandu, L. Dragomir, B. Pantelimon, Proc. of 15th IMEKO TC 4 Symposium, Interlaboratory comparison, 4 (2007)

20. O. Velychko, S. Karpenko, V. Gachok, Proc. of 19th Symp. IMEKO TC 4 Symp. and 17th IWADC Workshop Adv. in Instrumentation and Sensors Interoperability, Evaluation of the uncertainty of calibration of the three phase high precision comparator of the electrical power, 41-46 (2015)

21. S. Muravyov, I. Marinushkina, Meas. Tech., Processing data from interlaboratory comparisons by the method of preference aggregation, 6, 118-126 (2016)

22. P. Briggs, Proc. of 20th IMEKO World Cong., Proficiency testing for calibration laboratories, 5 (2012) 